Text: 2,544 words Abstract: 181 words

Tables: 5

\title{
Knowledge and attitudes of older psychiatric patients and their caregivers toward electroconvulsive therapy
}

Running title: ECT for older adults

1, 2\# Qing-E Zhang, MD

${ }^{1 \#}$ Fu-Chun Zhou, MD, PhD

${ }^{1 \#}$ Ling Zhang, MD, PhD

${ }^{3}$ Chee $\mathrm{H}$. Ng, MBBS, MD

${ }^{4}$ Gabor S. Ungvari, MD, PhD

$1 *$ Gang Wang, MD

2* Yu-Tao Xiang, MD, PhD

1. The National Clinical Research Center for Mental Disorders \& Beijing Key Laboratory of Mental Disorders, Beijing Anding Hospital, Capital Medical University, Beijing, China;

2. Faculty of Health Sciences, University of Macau, Macao SAR, China;

3. Department of Psychiatry, University of Melbourne, Melbourne, Victoria, Australia;

4. University of Notre Dame Australia / Graylands Hospital, Perth, Australia

\# These authors contributed equally to the paper.

*Address correspondence to Yu-Tao Xiang, 3/F, Building E12, Faculty of Health Sciences, University of Macau, Avenida da Universidade, Taipa, Macau SAR, China. Fax: +853-2288-2314; Phone: +853-8822-4223; E-mail: xyutly@gmail.com; or Dr. Gang Wang, Mood Disorders Center, Beijing Anding Hospital, Beijing, China. E-mail: gangwangdoc@gmail.com.

This is the author manuscript accepted for publication and has undergone full peer review but has not been through the copyediting, typesetting, pagination and proofreading process, which may lead to differences between this version and the Version of Record. Please cite this article as doi: $10.1111 /$ psyg.12326

This article is protected by copyright. All rights reserved. 


\section{ABSTRACT}

Background Electroconvulsive therapy (ECT) is an effective treatment for older patients with severe psychiatric disorders, but their knowledge and attitude toward ECT have not been well-studied. This study examined the knowledge and attitudes of Chinese older patients and their caregivers toward ECT.

Method A total of 216 participants, including older patients treated with ECT $(n=108)$ and their caregivers $(n=108)$, were recruited. Their knowledge and attitudes regarding ECT were assessed using self-reported questionnaires.

Results While most caregivers received sufficient information on the therapeutic effects of ECT, inadequate information was provided to caregivers and patients before treatment about the ECT process, its adverse effects and risks. Although ECT was generally viewed as beneficial, effective and safe, around two thirds of patients and caregivers believed that ECT should only be used for critically ill patients. Over half of the patients reported adverse effects caused by ECT, with memory impairment being the most commonly reported.

Conclusions Clinicians in Chinese psychiatric hospitals need to provide sufficient information of ECT to older patients and their caregivers prior to the treatment, particularly the treatment process and adverse effects.

Key words: attitudes, caregivers, electroconvulsive therapy, knowledge, older 
patients

This article is protected by copyright. All rights reserved. 


\section{INTRODUCTION}

Electroconvulsive therapy (ECT) is widely used in treating severe psychiatric disorders, including depression, bipolar disorders and schizophrenia. ${ }^{1,2}$ Although the mechanism of ECT remains unclear, it is effective particularly for those who are unresponsive to pharmacotherapy or unable to tolerate medications. ${ }^{3,4}$ However, ECT can also result in adverse effects, such as transient memory impairment which may restrict its use in older patients. ${ }^{5-7}$

Knowledge and attitude of patients and their caregivers toward ECT could significantly influence its acceptance and use of ECT in clinical practice. ${ }^{8,9}$ Misconceptions and negative attitudes toward ECT due to the incorrect portrayal of ECT in mass media, irrational fears of electricity, and excessive fear of memory loss have often created controversy around ECT. ${ }^{8,10,11}$ Studies in past decades have reassuringly found that the attitude of patients and their relatives toward ECT are usually positive. ${ }^{12-15}$ Although ECT is often used in older patients, their attitude and knowledge toward ECT have not been well-studied. One study in India found that older patients with severe psychiatric disorders had poor knowledge and negative attitude toward ECT. ${ }^{16}$

The number of older patients receiving ECT is very large in China; a survey of older patients with psychiatric disorders found that $28.1 \%$ received ECT, with the corresponding figures of $37.9 \%$ for bipolar disorders, $43.6 \%$ for major depression, 
$21.2 \%$ for schizophrenia and $10.7 \%$ for other disorders. ${ }^{17}$ However, there is ongoing debate about ECT use in China with some advocating its use to rapidly improve psychiatric symptoms ${ }^{18}$ while others arguing that it should be strictly controlled due to its risk of adverse effects. ${ }^{19}$ In order to understand the acceptance of ECT among older patients, it is important to examine patients' and caregivers' attitude and knowledge toward ECT. In addition, given the strong influence of sociocultural factors, $8,9,20$ the findings of attitude and knowledge toward ECT obtained in other settings could not be generalized to China. To date, there has only been one Chinese study published which found positive attitudes of patients and their relatives toward ECT. ${ }^{9}$ However, no data on older patients and their caregivers have yet been reported.

The aim of this study was to examine the knowledge and attitudes of Chinese older patients and their caregivers toward ECT, as well as the patients' subjective experience of ECT.

\section{METHODS}

Study design and participants

The study was a cross-sectional survey conducted between June 1, 2016 and July 31, 2017 in Beijing Anding Hospital which serves 20 million people in northern China. The hospital provides 800 psychiatric beds, 1,500 outpatient consultations daily and 
around 1,500 ECT treatments monthly. The study protocol was approved by the Research and Ethics Committee of Beijing Anding Hospital. All participants provided written informed consent.

Patients and their caregivers were invited to participate in this survey. All patients fulfilled the following inclusion criteria: 1) diagnosis of schizophrenia or bipolar disorder or major depression according to International Classification of Diseases, 10th Revision (ICD-10) based on a review of medical records and a clinical interview (these diagnoses accounted for over $90 \%$ of inpatients in the psychogeriatric ward of this hospital, while the remaining had behavioural and psychological symptoms of dementia); 2) aged 55 years or older. Although patients aged $\geqslant 60$ or 65 years are defined as 'older patients' according to international consensus, in this local hospital setting patients aged $\geqslant 55$ were eligible to receive treatment in the psychogeriatric department; 3) received ECT in the past six months, but the last ECT treatment completed at least four weeks prior to this survey; 4) able to understand the content of the survey; 5) did not have cognitive impairment as judged by the treating psychiatrist. In China, most clinically stable older psychiatric patients could not be discharged into the community because of the lack of community services and their family members are unable to provide appropriate care. Therefore, a lot of patients were still in the hospital even after 4 weeks had passed since the end of the ECT treatment. Inclusion criteria for the caregivers were 
as follows: 1) identified as family members or friends who provided primary personal care for the patients in the past six months; 2 ) aged at least 18 years; 3 ) able to communicate and understand the content of the survey; 4) did not have cognitive impairment as judged by the treating psychiatrist.

\section{ECT Parameters}

The ECT was only provided for inpatients and was delivered by the ECT Unit in Beijing Anding Hospital. A course of ECT, prescribed by treating psychiatrists, usually comprises 6-12 sessions under general anesthesia. Traditionally, 5 treatments were conducted in the first week, and subsequently two or three times per week. Anesthesia included the use of succinylcholine $(0.3-0.7 \mathrm{mg} / \mathrm{kg})$, propofol (1-1.5 mg/kg), and mask oxygen inhalation. A square-wave equipment (Spectrum 5000Q ECT machine, MECTA Corp., Lake Oswego, OR, USA) provided the stimulus intensity standardized at $900 \mathrm{~mA}$ for $1-8$ s using bitemporal electrode placement in all sessions. Electroencephalography was used to monitor the seizures.

\section{ECT Consent Process}

According to the regulations of this hospital, all patients needed to consent to ECT at least verbally, while their caregivers must all provide written informed consent prior to ECT. Moderate to severe adverse events, such as sudden death, allergic reaction 
to anesthesia, or bone/teeth fracture, were included in the informed consent forms in the ECT Unit of this hospital.

\section{Assessments}

Demographic and clinical data of patients were collected using a data collection form designed for the study based on an interview and a review of medical records. A self-reported questionnaire for patients was administered consisting of three sections: 1) questions about subjective experience of ECT; 2) knowledge and attitudes towards ECT; 3 ) adverse effects of ECT. Another questionnaire with similar contents on the knowledge of and attitudes toward ECT was given to the caregivers. There were 3 options for each item including "agree/yes," "disagree/no," and "I don't know." Similar questionnaires were used previously in other studies. ${ }^{9,21}$

\section{Statistical analysis}

Data were analyzed by the Statistical Package for Social Sciences (SPSS), version 21.0. Chi-square tests were used to compare the differences of the knowledge of and attitudes towards ECT between patients and caregivers. The level of significance was set at 0.05 (two-tailed test).

\section{RESULTS}


Basic demographic and clinical characteristics

All patients were hospitalized prior to having a course of ECT. Out of all inpatients, only 150 patients received ECT during the study period; of them, 122 were invited to participate in the survey but 4 refused participation. Therefore, finally 118 patients and 118 caregivers fulfilled the study entry criteria and completed the assessment, giving a participation rate of $96.7 \%$. Of the patients, $77.1 \%$ were diagnosed with major depressive disorder, $14.4 \%$ with bipolar disorder and $8.5 \%$ with schizophrenia. Most patients were females $(71.2 \%) ; 62.7 \%$ of patients had primary and junior secondary school education. The mean age, age of illness onset and duration of illness were $63.6 \pm 4.5$ years, $50.0 \pm 13.7$ years and $15.3 \pm 19.0$ years, respectively. The mean number of ECT was $6.7 \pm 2.3$. Most patients received antidepressants $(81.8 \%)$ followed by antipsychotics $(48.2 \%)$ while receiving ECT (Table 1).

\section{Patients' and caregivers' knowledge of ECT}

Most caregivers reported they had received adequate information on the therapeutic effects of ECT, but the adequacy of information provided to patients was less. In contrast, the information about the ECT process, adverse effects and risks provided prior to the ECT was inadequate to both caregivers and patients. Older patients and caregivers both had the view that ECT was more effective and quicker 
acting than drugs (Table 2).

\section{Patients and Caregivers' Attitudes toward ECT}

Most patients and caregivers reported positive attitudes toward ECT. They endorsed the statement that ECT was safe and could be used again if necessary. Also, they did not view that ECT is a punitive treatment or should only be used as the last resort. However, around two thirds of patients and caregivers had the view that ECT should be used for critically ill patients. More caregivers than patients had endorsed the statement "Would you/your relative like to receive ECT again?", $(P<0.05)$ (Tables 3). Of note, $81.3 \%$ of patients were worried during the ECT treatment, particularly in the following settings: "Waiting for the treatment" $(39.3 \%), "$ Wearing an oxygen mask" (29.9\%), and "Thinking of the treatment associated with electricity" (25.2\%) (Table 4).

\section{Patients' Experience of Adverse Effects of ECT}

Altogether, $57 \%$ of the patients reported adverse effects associated with ECT treatment; the most common adverse effects included memory impairment $(62.6 \%)$, headache (33.6\%) and muscle pain (29.9\%) (Table 5).

\section{DISCUSSION}


Previously, a survey in Asia found that the most common indications for ECT were schizophrenia (41.8\%), major depression (32.4\%) and mania (14.0\%). ${ }^{22}$ In this study, however, $77.1 \%$ of the patients treated by ECT were diagnosed with major depressive disorder, $14.4 \%$ with bipolar disorder and $8.5 \%$ with schizophrenia, which is consistent with the convention that treatment-resistant mood disorders is the main indication for ECT in China. ${ }^{23,24}$ Not surprisingly, this study found that most patients received antidepressants, while the minority received mood stabilizers and benzodiazepines during ECT. Benzodiazepines and mood stabilizers could raise seizure threshold, which negatively impacts on the efficacy of ECT and should therefore be avoided or reduced where possible. ${ }^{25,26}$ In this study, around half of the patients received antipsychotic medications, although only $22.9 \%$ were diagnosed with schizophrenia or bipolar disorder. As this hospital mainly served patients with acute and severe psychiatric disorders, many patients with major depression had psychotic symptoms which justified the high percentage of antipsychotic use.

The mean number of ECT sessions was $6.7 \pm 2.3$, which was in the lower range of the usual recommended number of sessions (6-12) in treatment guidelines in China. ${ }^{24}$ The possible reasons may include the poor general health in older patients who may not tolerate many ECT sessions. ${ }^{17}$ Poor general health and advanced age are not contraindications for ECT in China. However, poor general health in older 
patients is often associated with increased risk of anesthesia-related complications, therefore fewer numbers of ECT sessions are recommended in Chinese guidelines. ${ }^{24}$ In addition, there is an association between older age and more rapid remission after ECT, particularly for depressed patients. ${ }^{27}$ Finally, older patients may be more vulnerable to pre-existing cognitive impairment ${ }^{5}$ and have more severe cognitive side effects of ECT than adult patients ${ }^{3,28}$ which may limit the number of ECT sessions prescribed. Apart from reducing the number of treatments, unilateral electrode placement is also associated with less severe memory impairment than bitemporal electrode placement. ${ }^{29}$

Similar to previous findings in adult patients, $9,30,31$ the majority of older patients and their caregivers appear to receive adequate information about the therapeutic effects of ECT. However, inadequate information was provided about the ECT process, adverse effects and risks prior to ECT. In China, hospitalized older patients were prescribed ECT after their caregivers had signed the consent form which was permissible under the mental health legislation in China. ${ }^{32}$ Hence, hospitalized older patients' understanding and knowledge were often neglected in clinical practice.

Misconceptions about ECT are common, which is a major reason limiting its use in many countries. ${ }^{33}$ The negative public image of ECT was believed to originate in early 1970 s when it was seen as an inhumane and punitive treatment. ${ }^{15,34}$ Mass media including print and films have also contributed significantly to the negative 
attitude toward ECT while inadequate information about ECT was provided by the mental health professionals. ${ }^{8,16}$ In this study, older patients and caregivers mostly reported positive attitudes and they agreed that ECT is safe and could be used again if necessary. Unlike many Western countries, ECT has been used for decades in China with little controversy since prior to 1980 s Chinese psychiatry had been isolated from the international psychiatric community. ${ }^{35}$ With increasing expertise and implementation of clinical best practice, ECT has been frequently prescribed and highly acceptable by patients and clinicians in China. ${ }^{35}$ However, we found that the vast majority of older patients reported being worried during the ECT, particularly while waiting for the treatment, wearing oxygen masks, and associating the treatment with electricity. Hence, clinicians in Chinese psychiatric hospitals should provide education about ECT, including the nature of the treatment, medical procedures and common adverse effects.

A review of 36 studies has found that around two thirds of patients who received ECT experienced adverse effects, ${ }^{36}$ which is consistent with this study. This did not appear to cause negative attitudes possibly because ECT side effects were mild, transient and well tolerated by patients. ${ }^{37,38}$ Of the adverse effects, memory impairment is the most common concern to patients. ${ }^{38-40}$ About two thirds of older patients reported memory impairment in our study, which similar to the figure $(65.7 \%)$ reported in adult studies. ${ }^{9}$ 
The results should be interpreted with caution due to several limitations. First, no standardized interviewer-based instruments on knowledge and attitudes towards ECT were available, thus following other studies ${ }^{9,21}$ only a self-reported questionnaire was used with all its obvious limitations. Second, the findings could not be applied to all areas in China since participants were only recruited from one major city hospital. Third, some variables influencing attitudes of patients toward ECT, such as illness severity and use of psychotropic medications, were not included.

In conclusion, older patients and their caregivers reported positive attitudes toward ECT and satisfaction with its therapeutic effects. However, information provided about the treatment process and adverse effects of ECT were lacking. Adequate information about ECT should be provided by Chinese psychiatric hospital clinicians to both older patients and caregivers. 


\section{Competing Financial Interests}

The authors had no conflicts of interest in conducting this study or preparing the manuscript.

\section{Acknowledgements}

The study was supported in part by grants from the Beijing Municipal Administration of Hospitals Incubating Program (code: PX2016016), the Capital City Clinical Practice and Research Funding of Beijing Municipal Science \& Technology Commission (Z141107002514033; Z151100004015042), the Clinical Medicine Development Funding of Beijing Municipal Administration of Hospitals (ZYLX201403; ZYLX201607), and Beijing Municipal Administration of Hospital's Ascent Plan (DFL20151801). 


\section{REFERENCE}

1. Rasmussen K. The practice of electroconvulsive therapy: recommendations for treatment, training, and privileging. The journal of ECT 2002; 18: 58-59.

2. Bauer M, Bschor T, Pfennig A, et al. World Federation of Societies of Biological Psychiatry (WFSBP) guidelines for biological treatment of unipolar depressive disorders in primary care. The World Journal of Biological Psychiatry 2007; 8: 67-104.

3. Benbow SM, Waite J, Easton A. ECT for older adults: The Royal College of Psychiatrists London; 2013.

4. Kerner N, Prudic J. Current electroconvulsive therapy practice and research in the geriatric population. Neuropsychiatry $2014 ; 4: 33-54$.

5. Dybedal GS, Tanum L, Sundet K, Gaarden TL, Bjolseth TM. Cognitive side-effects of electroconvulsive therapy in elderly depressed patients. The Clinical neuropsychologist 2014; 28: 1071-1090.

6. Manly DT, Oakley SP, Jr., Bloch RM. Electroconvulsive therapy in old-old patients. Am J Geriatr Psychiatry 2000; 8: 232-236.

7. Henstra MJ, Jansma EP, van der Velde N, Swart EL, Stek ML, Rhebergen D. Acetylcholinesterase inhibitors for electroconvulsive therapy-induced cognitive side effects: a systematic review. Int J Geriatr Psychiatry 2017; 32: 522-531.

8. Tang $\mathrm{YL}$, Jiang $\mathrm{W}$, Ren $\mathrm{YP}, \mathrm{Ma} \mathrm{X}$, Cotes RO, McDonald WM. Electroconvulsive 
therapy in China: clinical practice and research on efficacy. J ECT 2012; 28: 206-212.

9. Li Y, An FR, Zhu H, et al. Knowledge and Attitudes of Patients and Their Relatives Toward Electroconvulsive Therapy in China. Perspect Psychiatr Care 2016; 52: 248-253.

10. McDonald A, Walter G. The portrayal of ECT in American movies. J ECT 2001; 17: 264-274.

11. AlHadi AN, AIShahrani FM, Alshaqrawi AA, Sharefi MA, Almousa SM. Knowledge of and attitudes towards electroconvulsive therapy (ECT) among psychiatrists and family physicians in Saudi Arabia. Annals of general psychiatry 2017; 16: 16.

12. Brodaty H, Berle D, Hickie I, Mason C. Perceptions of outcome from electroconvulsive therapy by depressed patients and psychiatrists. Aust $N Z \mathrm{~J}$ Psychiatry 2003; 37: 196-199.

13. Goodman JA, Krahn LE, Smith GE, Rummans TA, Pileggi TS. Patient satisfaction with electroconvulsive therapy. Mayo Clin Proc 1999; 74: 967-971.

14. Rajkumar AP, Saravanan B, Jacob K. Perspectives of patients and relatives about electroconvulsive therapy: a qualitative study from Vellore, India. The journal of ECT 2006; 22: 253-258.

15.Dowman J, Patel A, Rajput K. Electroconvulsive therapy: attitudes and misconceptions. The journal of ECT 2005; 21: 84-87. 
16. Grover S, Chakrabarti S, Avasthi A. Knowledge about and attitude toward electroconvulsive therapy of elderly patients with severe mental disorders. Journal of Geriatric Mental Health 2014; 1: 100.

17. Zhang $X Q$, Wang $Z M$, Pan $Y L$, et al. Use of electroconvulsive therapy in older Chinese psychiatric patients. Int J Geriatr Psychiatry 2015; 30: 851-856.

18. Huang J, Gao YX, Liu DF. Modified electroconvulsive therapy for bipolar disorders (in Chinese). Journal of Clinical Psychological Medicine 2010; 20: 57.

19. Chung KF. Electroconvulsive therapy in Hong Kong: rates of use, indications, and outcome. J ECT 2003; 19: 98-102.

20. Gazdag G, Takács R, Tolna J, Iványi Z, Ungvari GS, Bitter I. Electroconvulsive therapy in a Hungarian academic centre (1999-2010). Psychiatria Danubina 2013;

25: $0-370$.

21. Tang WK, Ungvari GS, Chan GW. Patients' and their relatives' knowledge of, experience with, attitude toward, and satisfaction with electroconvulsive therapy in Hong Kong, China. J ECT 2002; 18: 207-212.

22. Chanpattana W, Kramer BA, Kunigiri G, Gangadhar BN, Kitphati R, Andrade C. A survey of the practice of electroconvulsive therapy in Asia. J ECT 2010; 26: 5-10. 23. Chinese Medical Association. Guideline for the Prevention and Treatment of Psychiatric Disorders in China. Beijing: Chinese Medical Association; 2003. 24. Shen YC. Psychiatry. Beijing: People's Medical Publishing House; 2009. 
25. Kay J, Knapp VR, Bienenfeld D. Electroconvulsive therapy. Psychiatry 2001; 5:

1.

26. Greenberg RM, Pettinati HM. Benzodiazepines and Electroconvulsive Therapy. The journal of ECT 1993; 9: 262-273.

27. Rhebergen D, Huisman A, Bouckaert F, et al. Older age is associated with rapid remission of depression after electroconvulsive therapy: a latent class growth analysis. The American Journal of Geriatric Psychiatry 2015; 23: 274-282.

28. Sackeim HA, Prudic J, Fuller R, Keilp J, Lavori PW, Olfson M. The cognitive effects of electroconvulsive therapy in community settings. Neuropsychopharmacology 2007; 32: 244.

29. Dunne RA, McLoughlin DM. Systematic review and meta-analysis of bifrontal electroconvulsive therapy versus bilateral and unilateral electroconvulsive therapy in depression. The World Journal of Biological Psychiatry 2012; 13: 248-258.

30. Virit O, Ayar D, Savas HA, Yumru M, Selek S. Patients' and their relatives' attitudes toward electroconvulsive therapy in bipolar disorder. The journal of ECT 2007; 23: 255-259.

31. Rose DS, Wykes TH, Bindman JP, Fleischmann PS. Information, consent and perceived coercion: patients' perspectives on electroconvulsive therapy. The British Journal of Psychiatry 2005; 186: 54-59.

32. Xiang YT, Yu X, Ungvari GS, Lee EH, Chiu HF. China's National Mental Health Law: 
a 26-year work in progress. Lancet $2012 ; 379: 780-782$.

33. Xiang YT, Ungvari GS, Correll CU, et al. Use of electroconvulsive therapy for Asian patients with schizophrenia (2001-2009): Trends and correlates. Psychiatry Clin Neurosci 2015; 69: 489-496.

34. Zhang X, Weng W, Lu H. [Discovery and brief developmental history of electro -convulsive therapy in mental diseases]. Zhonghua Yi Shi Za Zhi 2001; 31: 213-216. 35. Leung CM, Xiang YT, He JL, et al. Modified and unmodified electroconvulsive therapy: a comparison of attitudes between psychiatrists in Beijing and Hong Kong. J ECT 2009; 25: 80-84.

36. Chakrabarti S, Grover S, Rajagopal R. Electroconvulsive therapy: a review of knowledge, experience and attitudes of patients concerning the treatment. The world journal of biological psychiatry : the official journal of the World Federation of Societies of Biological Psychiatry 2010; 11: 525-537.

37. Hausner L, Damian M, Sartorius A, Frolich L. Efficacy and cognitive side effects of electroconvulsive therapy (ECT) in depressed elderly inpatients with coexisting mild cognitive impairment or dementia. J Clin Psychiatry 2011; 72: 91-97.

38. Tielkes CE, Comijs HC, Verwijk E, Stek ML. The effects of ECT on cognitive functioning in the elderly: a review. Int J Geriatr Psychiatry 2008; 23: 789-795. 39. Kershaw K, Rayner L, Chaplin R. Patients' views on the quality of care when receiving electroconvulsive therapy. The Psychiatrist 2007; 31: 414-417. 
40. Myers DH. A questionnaire study of patients' experience of electroconvulsive therapy. The journal of ECT 2007; 23: 169-174. 
Table 1. Basic demographic and clinical characteristics of patients receiving ECT

\begin{tabular}{|c|c|c|}
\hline \multirow[t]{2}{*}{ Variables } & \multicolumn{2}{|c|}{ The whole sample $(n=118)$} \\
\hline & $\mathrm{N}$ & $\%$ \\
\hline Male gender & 34 & 28.8 \\
\hline Married & 102 & 86.4 \\
\hline \multicolumn{3}{|l|}{ Education } \\
\hline Junior secondary school and below & 74 & 62.7 \\
\hline senior secondary school & 31 & 26.3 \\
\hline College and above & 13 & 11.0 \\
\hline \multicolumn{3}{|l|}{ Principal diagnosis } \\
\hline Schizophrenia & 10 & 8.5 \\
\hline Major depression & 91 & 77.1 \\
\hline Bipolar disorder & 17 & 14.4 \\
\hline Past ECT treatment & 34 & 28.8 \\
\hline First hospitalization & 27 & 22.9 \\
\hline On antipsychotics & 53 & 48.2 \\
\hline On FGAs & 2 & 1.8 \\
\hline On SGAs & 51 & 46.4 \\
\hline On antidepressants & 90 & 81.8 \\
\hline On benzodiazepines & 14 & 12.7 \\
\hline \multirow[t]{2}{*}{ On mood stabilizers } & 14 & 12.7 \\
\hline & Mean & SD \\
\hline Age (years) & 63.6 & 4.5 \\
\hline Age of onset (years) & 50.0 & 13.7 \\
\hline Duration of illness (years) & 15.3 & 19.0 \\
\hline Hospital duration (days) & 38.2 & 15.7 \\
\hline Number of hospitalizations & 2.0 & 1.3 \\
\hline Number of ECT sessions in the recent hospitalization & 6.7 & 2.3 \\
\hline
\end{tabular}

ECT: electroconvulsive therapy. FGAs: first-generation antipsychotics; SGAs: second-generation antipsychotics

This article is protected by copyright. All rights reserved. 
Table 2. Patients' and caregivers' knowledge and views of ECT

\begin{tabular}{|c|c|c|c|c|c|c|}
\hline \multirow{2}{*}{ Items } & \multicolumn{2}{|c|}{ Patients } & \multicolumn{2}{|c|}{ Caregivers } & \multicolumn{2}{|c|}{ statistic } \\
\hline & $\mathrm{n}$ & $\%$ & $\mathrm{n}$ & $\%$ & $x^{2}$ & $p$ \\
\hline 1) Were you given any information before ECT? & & & & & 16.5 & $<0.001$ \\
\hline Disagree & 33 & 30.8 & 15 & 13.9 & & \\
\hline Agree & 56 & 52.3 & 85 & 78.5 & & \\
\hline Don't know & 18 & 16.8 & 8 & 7.4 & & \\
\hline $\begin{array}{l}\text { 2) Were you given adequate information concerning the } \\
\text { therapeutic effects of ECT? }\end{array}$ & & & & & 10.1 & 0.006 \\
\hline Disagree & 30 & 28.0 & 13 & 12.0 & & \\
\hline Agree & 60 & 56.1 & 81 & 75.0 & & \\
\hline Don't know & 17 & 15.9 & 14 & 13.0 & & \\
\hline $\begin{array}{l}\text { 3) Were you given adequate information concerning the } \\
\text { process of ECT? }\end{array}$ & & & & & 1.7 & 0.41 \\
\hline Disagree & 39 & 36.4 & 33 & 30.6 & & \\
\hline Agree & 41 & 38.3 & 51 & 47.2 & & \\
\hline Don't know & 27 & 25.2 & 24 & 22.2 & & \\
\hline $\begin{array}{l}\text { 4) Were you given adequate information concerning the } \\
\text { side effects of ECT? }\end{array}$ & & & & & 8.4 & 0.01 \\
\hline Disagree & 37 & 34.6 & 24 & 22.2 & & \\
\hline Agree & 34 & 31.8 & 55 & 50.9 & & \\
\hline Don't know & 36 & 33.6 & 29 & 26.9 & & \\
\hline $\begin{array}{l}\text { 5) Were you given adequate information concerning the } \\
\text { risks of ECT? }\end{array}$ & & & & & 12.2 & 0.002 \\
\hline Disagree & 44 & 41.1 & 24 & 22.2 & & \\
\hline Agree & 27 & 25.2 & 49 & 45.4 & & \\
\hline Don't know & 36 & 33.6 & 35 & 32.4 & & \\
\hline $\begin{array}{l}\text { 6) Do you think health professionals provide adequate } \\
\text { information about ECT? }\end{array}$ & & & & & 8.2 & 0.01 \\
\hline Disagree & 26 & 24.3 & 12 & 11.1 & & \\
\hline Agree & 57 & 53.3 & 76 & 70.4 & & \\
\hline Don't know & 24 & 22.4 & 20 & 18.5 & & \\
\hline 7) Do you feel ECT has been beneficial? & & & & & 8.6 & 0.01 \\
\hline Disagree & 10 & 9.3 & 3 & 2.8 & & \\
\hline Agree & 80 & 74.8 & 97 & 89.8 & & \\
\hline Don't know & 17 & 15.9 & 8 & 7.4 & & \\
\hline 8) Do you feel ECT has made you/your relative worse? & & & & & 2.8 & 0.24 \\
\hline Disagree & 69 & 64.5 & 75 & 69.4 & & \\
\hline Agree & 14 & 13.1 & 18 & 16.7 & & \\
\hline Don't know & 24 & 22.4 & 15 & 13.9 & & \\
\hline 9) Do you feel ECT has been more effective than drugs? & & & & & 0.3 & 0.82 \\
\hline Disagree & 10 & 9.3 & 8 & 7.4 & & \\
\hline Agree & 71 & 66.4 & 71 & 65.7 & & \\
\hline Don't know & 26 & 24.3 & 29 & 26.9 & & \\
\hline $\begin{array}{l}\text { 10) Do you think the effect of ECT is more rapid than } \\
\text { drugs? }\end{array}$ & & & & & 2.8 & 0.24 \\
\hline Disagree & 8 & 7.5 & 8 & 7.4 & & \\
\hline
\end{tabular}

This article is protected by copyright. All rights reserved. 


\begin{tabular}{|l|l|l|l|l|l|l|}
\hline Agree & 69 & 64.5 & 80 & 74.1 & & \\
\hline Don't know & 30 & 28.0 & 20 & 18.5 & & \\
\hline
\end{tabular}

ECT: electroconvulsive therapy. 
Table 3. Patients' and caregivers' attitudes toward ECT

\begin{tabular}{|c|c|c|c|c|c|c|}
\hline \multirow{2}{*}{ Items } & \multicolumn{2}{|c|}{ Patients } & \multicolumn{2}{|c|}{ Caregivers } & \multicolumn{2}{|c|}{ Statistics } \\
\hline & $\mathrm{n}$ & $\%$ & $\mathrm{n}$ & $\%$ & $x^{2}$ & $p$ \\
\hline 1) Is ECT safe? & & & & & 9.8 & 0.007 \\
\hline Disagree & 14 & 13.1 & 2 & 1.9 & & \\
\hline Agree & 70 & 65.4 & 80 & 74.1 & & \\
\hline Don't know & 23 & 21.5 & 26 & 24.1 & & \\
\hline 2) Does ECT generate fear? & & & & & 1.4 & 0.48 \\
\hline Disagree & 63 & 58.9 & 63 & 58.3 & & \\
\hline Agree & 29 & 27.1 & 24 & 22.2 & & \\
\hline Don't know & 15 & 14.0 & 21 & 19.4 & & \\
\hline 3) Do you think ECT is more dangerous than drugs? & & & & & 1.2 & 0.54 \\
\hline Disagree & 56 & 52.3 & 51 & 47.2 & & \\
\hline Agree & 36 & 33.6 & 36 & 33.3 & & \\
\hline Don't know & 15 & 14.0 & 21 & 19.4 & & \\
\hline $\begin{array}{l}\text { 4) Do you think ECT is dangerous and should not be } \\
\text { used? }\end{array}$ & & & & & 2.7 & 0.25 \\
\hline Disagree & 77 & 72.0 & 88 & 81.5 & & \\
\hline Agree & 8 & 7.5 & 5 & 4.6 & & \\
\hline Don't know & 22 & 20.6 & 15 & 13.9 & & \\
\hline 5) Is ECT used for people who don't need it? & & & & & 0.2 & 0.88 \\
\hline Disagree & 50 & 46.7 & 48 & 44.4 & & \\
\hline Agree & 12 & 11.2 & 11 & 10.2 & & \\
\hline Don't know & 45 & 42.1 & 49 & 45.4 & & \\
\hline 6) Is ECT used for critically ill patients? & & & & & 0.3 & 0.84 \\
\hline Disagree & 24 & 22.4 & 24 & 22.2 & & \\
\hline Agree & 61 & 57.0 & 65 & 60.2 & & \\
\hline Don't know & 22 & 20.6 & 19 & 17.6 & & \\
\hline 7) Should ECT be the last resort? & & & & & 0.1 & 0.94 \\
\hline Disagree & 47 & 43.9 & 45 & 41.7 & & \\
\hline Agree & 29 & 27.1 & 31 & 28.7 & & \\
\hline Don't know & 31 & 29.0 & 32 & 29.6 & & \\
\hline 8) Is ECT used to punish patients? & & & & & 0.5 & 0.76 \\
\hline Disagree & 88 & 82.2 & 88 & 81.5 & & \\
\hline Agree & 3 & 2.8 & 5 & 4.6 & & \\
\hline Don't know & 16 & 15.0 & 15 & 13.9 & & \\
\hline 9) Would you/your relative like to receive ECT again? & & & & & 6.4 & 0.04 \\
\hline Disagree & 19 & 17.8 & 10 & 9.3 & & \\
\hline
\end{tabular}

This article is protected by copyright. All rights reserved. 


\begin{tabular}{|l|l|l|l|l|l|l|}
\hline Agree & 58 & 54.2 & 76 & 70.4 & & \\
\hline Don't know & 30 & 28.0 & 22 & 20.4 & & \\
\hline
\end{tabular}

ECT: electroconvulsive therapy. 
Table 4. Patients' experience in ECT process

\begin{tabular}{|l|c|c|c|c|}
\hline & \multicolumn{4}{|c|}{ patients } \\
\hline What made you worried during the process of ECT? & \multicolumn{2}{|c|}{ yes } & \multicolumn{2}{c|}{ no } \\
\hline & $\mathrm{n}$ & $\%$ & $\mathrm{n}$ & $\%$ \\
\hline Did you feel worried? & 87 & 81.3 & 20 & 16.9 \\
\hline 1) Waiting for the treatment & 32 & 29.9 & 75 & 70.1 \\
\hline 2) Wearing an oxygen mask & 27 & 25.2 & 80 & 74.8 \\
\hline 3) Being tied with a headband & 9 & 8.4 & 98 & 91.6 \\
\hline 4) Being injected intravenously & 7 & 6.5 & 100 & 93.5 \\
\hline 5) Being in a comatose state & 19 & 17.8 & 88 & 82.2 \\
\hline 6) Waking up after the treatment & 23 & 21.5 & 84 & 78.5 \\
\hline $\begin{array}{l}\text { 7)Thinking of the treatment being associated with } \\
\text { electricity }\end{array}$ & 42 & 39.3 & 65 & 60.7 \\
\hline
\end{tabular}

This article is protected by copyright. All rights reserved. 
Table 5.Patients' experience of adverse effects of ECT

\begin{tabular}{|l|c|c|c|c|c|c|}
\hline \multirow{2}{*}{} & \multicolumn{2}{|c|}{ patients } \\
\cline { 3 - 8 } & \multicolumn{2}{|c|}{ disagree } & \multicolumn{2}{c|}{ agree } & \multicolumn{2}{c|}{ Don't know } \\
\cline { 2 - 8 } & $\mathrm{n}$ & $\%$ & $\mathrm{n}$ & $\%$ & $\mathrm{n}$ & $\%$ \\
\hline 1) Have you had any adverse effects? & 23 & 21.5 & 61 & 57.0 & 23 & 21.5 \\
\hline 2) Did you have headache? & 65 & 60.7 & 36 & 33.6 & 6 & 5.6 \\
\hline 3) Did you have muscle pain? & 68 & 63.6 & 32 & 29.9 & 7 & 6.5 \\
\hline 4) Did you have poor appetite or nausea? & 89 & 83.2 & 11 & 10.3 & 7 & 6.5 \\
\hline 5) Did you have short-lived confusion? & 82 & 76.6 & 15 & 14.0 & 10 & 9.3 \\
\hline 6) Did you have memory impairment? & 34 & 31.8 & 67 & 62.6 & 6 & 5.6 \\
\hline
\end{tabular}




\section{University Library}

\section{- M M N E R VA A gateway to Melbourne's research publications}

Minerva Access is the Institutional Repository of The University of Melbourne

Author/s:

Zhang, Q-E;Zhou, F-C;Zhang, L;Ng, CH;Ungvari, GS;Wang, G;Xiang, Y-T

Title:

Knowledge and attitudes of older psychiatric patients and their caregivers towards electroconvulsive therapy

Date:

2018-09-01

\section{Citation:}

Zhang, Q. -E., Zhou, F. -C., Zhang, L., Ng, C. H., Ungvari, G. S., Wang, G. \& Xiang, Y. -T. (2018). Knowledge and attitudes of older psychiatric patients and their caregivers towards electroconvulsive therapy. PSYCHOGERIATRICS, 18 (5), pp.343-350. https:// doi.org/10.1111/psyg.12326.

Persistent Link:

http://hdl.handle.net/11343/284209 